\title{
SMART CLASSROOM, INTERNET OF THINGS AND PERSONALIZED TEACHING Teodor Savov ${ }^{1}$, Valentina Terzieva ${ }^{2}$, Katia Todorova ${ }^{3}$, Petia Kademova-Katzarova ${ }^{4}$
}

\begin{abstract}
Nowadays, information and communication technologies (ICT) and the Internet of Things (IoT) are already ubiquitous in the field of education. They began significantly to change the way of teaching and learning. A large-scale online survey in Bulgarian schools shows that in most classrooms different innovative tools are available which allow technologyenhanced teaching. The next step is to integrate these resources and tools into a smart environment and to manage them through a control system. The authors provide a conceptual framework for the development of an integrated technology-rich learning environment that is supervised by a control module within a contemporary smart classroom. In particular, the paper presents in detail a technical solution for ensuring the communication process between students and the teacher as well as allowing the involvement of parents in the educational process. Additionally, some use cases of the smart classroom are outlined, along with discussions on the potential benefits for teachers, learners and parents.
\end{abstract}

UDC Classification: 004.9, DOI: 10.12955/cbup.v7.1491

Keywords: ICT, smart classroom, IoT, control system, personalized instructions

\section{Introduction}

Information and communication technologies (ICT) are a fundamental driver of the digital revolution from smart terminal devices to ultra-fast internet, mobile applications and research into emerging technologies. They are also an essential factor in building a competitive knowledge-based and inclusive information society. The widespread use of innovative technologies underpins and ensures the development of all socio-economic sectors, including education. The National Strategy Program ("Digital Bulgaria 2025," 2018) continues and upgrades the previous ("Strategy for Effective Implementation of Information and Communication Technologies in Education and Science," 2014) taking into account the new European strategic guidelines for achieving a smart, inclusive, sustainable and digital growth. The program aims to modernize and deploy intelligent solutions across all social and economic areas by creating an environment for the widespread use of ICT, national infrastructure, innovative e-services for business and all citizens, and a high level of networking. Thus, the field of education has to be transformed in accordance with those priorities. It is necessary to raise the level of digital skills of all participants in the economic sectors as well as students in order to improve their employability. There must be significant changes in the education system and especially in the way of training, as to be adapted to the digital generation. This can be ensured by four transformation activities: Providing adequate ICT infrastructure in schools; Modernization of the curriculums and methods of teaching; Improvement of technology skills of teachers; Development and assessment of pupils' digital competence.

As ICT is ubiquitous in all social and economic areas, including education, all these areas have begun significantly to change their way of functioning; the same is valid for the teaching process in schools. Technical competence and computer literacy have already become mandatory, so students have to be prepared for the requirements of the contemporary technological world. Therefore, it is necessitated to start learning from the earliest age in a technology-rich environment where teaching is technologyenhanced. The role of classroom equipment is significant, which must be in line with technological development. With regard to this indicator, the educational sphere is generally straggling. Many schools now have well-equipped classrooms where technology tools are used as educational tools. These include computers, tablets, interactive whiteboards (IWB), multimedia, and projectors. Some schools have even the most innovative virtual/augmented reality devices and specially equipped classrooms for science laboratories. Hence, in such a technology-rich educational environment a blend of traditional and technology-enhanced teaching-learning can be performed to build new skills that meet the requirements of today's society. The current research aims to provide a comprehensive solution - a conceptual model

\footnotetext{
${ }^{1}$ Institute of Information and Communication Technologies - Bulgarian Academy of Sciences, Sofia, Bulgaria, teodor_savov@isdip.bas.bg

${ }^{2}$ Institute of Information and Communication Technologies - Bulgarian Academy of Sciences, Sofia, Bulgaria, valia@isdip.bas.bg

${ }^{3}$ Institute of Information and Communication Technologies - Bulgarian Academy of Sciences, Sofia, Bulgaria, katia@isdip.bas.bg

${ }^{4}$ Institute of Information and Communication Technologies - Bulgarian Academy of Sciences, Sofia, Bulgaria, petia@isdip.bas.bg
} 
for integrating and managing all the technological equipment in contemporary schools, providing the functionality of a smart classroom.

\section{Literature Review}

The concept of smart education - a new paradigm of the digital age is the focus of much research. Zhu, $\mathrm{Yu}$ and Riezebos (2016) discuss definitions and propose a conceptual framework that includes three essential elements: smart environments, smart pedagogy, and smart learner.

With the development of technologies, the Internet of Things (IoT) and small gadgets are gaining increasing popularity. By enabling the connectivity of different devices to the Internet, IoT promotes the significant transformation of many economic and social areas by providing full connectivity (Rudd, Davia \& Sullivan, 2009). The education area is not left behind and various applications of IoT are involved in teaching practices - with the help of mobile technologies, e-learning has become a common practice in innovative schools and universities. Further, researchers such as Cata (2015) and Alghamdi and Shetty (2016) show that IoT allows improving safety by tracking students and controlling access to resources and information, which make the implementation of "smart" teaching methods easy. Students already use wearable and other personal devices with small sensors that can connect them with elearning systems and allow personalized access to learning resources (Nati et al., 2013). In many colleges and universities, traditional textbooks are replaced with tablets, equipped with interactive applications, enabling graphics and 3D simulations.

Most of the leading IT companies are developing technology applications based on IoT both for education and for other industries (Banks, 2015). Terzieva et al. (2017) offer a variety of IoT tools and technologies that support teaching in classrooms. Contemporary smart classrooms and schools are equipped with:

- Smart school environment control system - automatic management of room climate and lighting;

- Smart school security control system - wireless door locks, security cameras, RFID enabled student ID cards, biometric attendance tracking;

- Smart school e-learning system - interactive whiteboards, mobile devices (laptops, tablets, smartphones), library with e-resources, video conferencing facilities, virtual/ augmented reality, 3D scanners and printers.

Technology devices in such smart classrooms allow a richer learning experience for students and teachers and facilitate them in the editing and sharing of content, as well as the recording the lessons and publishing them online for further review and discussions. Banica et al. (2017) identified several practical methods for the integration of IoT features for the enhancement of teaching and learning. Ali et al. (2017) develop an IoT-based Flipped Learning Platform (IoTFLiP), based on the integration of existing IoT devices. This platform exploits features of IoT infrastructure to effectively support casebased learning in a flipped learning environment intended for medical education. Moreover, it provides necessary privacy measures for personalized medical data. ICT and IoT have a significant impact on the contemporary education system by transforming the infrastructure of educational institutions and putting into practice the concept of smart classrooms, smart schools and even smart campuses (Heinemann \& Uskov, 2018). These smart environments connect students and teachers and also enable the changing of traditional teaching approaches (Selinger et al., 2013).

Some of the well-known social responsible ICT companies develop and provide free smart educational resources, usually in English, but now there is an application especially intended for teachers and students in Bulgaria - Smart Classroom AR platform (http://www.smartclassroom.bg). It works on a smartphone and is very convenient and easy to use. Furthermore, its content is in line with the curriculum for students from grade 1 to 10 .

\section{ICT Equipment in Classrooms}

Rapid changes in technology inevitably lead to a change in society as well, offering new services. ICT is no longer just computers, mobile devices, sensors, and networks. They are now connected and form the basis for new concepts and socio-technological paradigms. In order to develop modern infrastructure in a field such as education, it is necessary to have technological prerequisites available. Therefore, the results of a study by Terzieva et al. (2018) are taken into consideration and summarized here. The survey, conducted during the school year 2017/2018 gives reliable results, as more than 1600 teachers from 
almost every area of Bulgaria took part. The current research shows the findings related to the type of ICT tools used - from the most common computers and interactive boards to the most innovative virtual reality as well as their actual use according to the teachers' points of view.

The implementation of ICT in schools is examined according to the technological tools applied in teaching practice in the classrooms. Teachers most often report the use of computers, multimedia systems, projectors, e-textbooks and workbooks, learning materials from educational websites, and various learning games. The prime motivation is to meet the expectations of the students of the digital generation so as to improve their engagement in the educational process. Nearly $40 \%$ of teachers in all subjects claim to use computers and about a quarter - projectors and web-based learning resources (Figure 1). The lessons in foreign language, mathematics and science often benefit from such tools. About 22\% of the respondents also use multimedia and electronic version of traditional textbooks in teaching many subjects. Only about $10 \%$ of teachers rely on interactive whiteboards in their classroom activities. The tools that mostly attract students- virtual/ augmented reality and simulators are very rarely available in classrooms. Recently, educational games gain popularity $-35 \%$ of teachers arrange lessons with them (predominantly - primary school teachers).

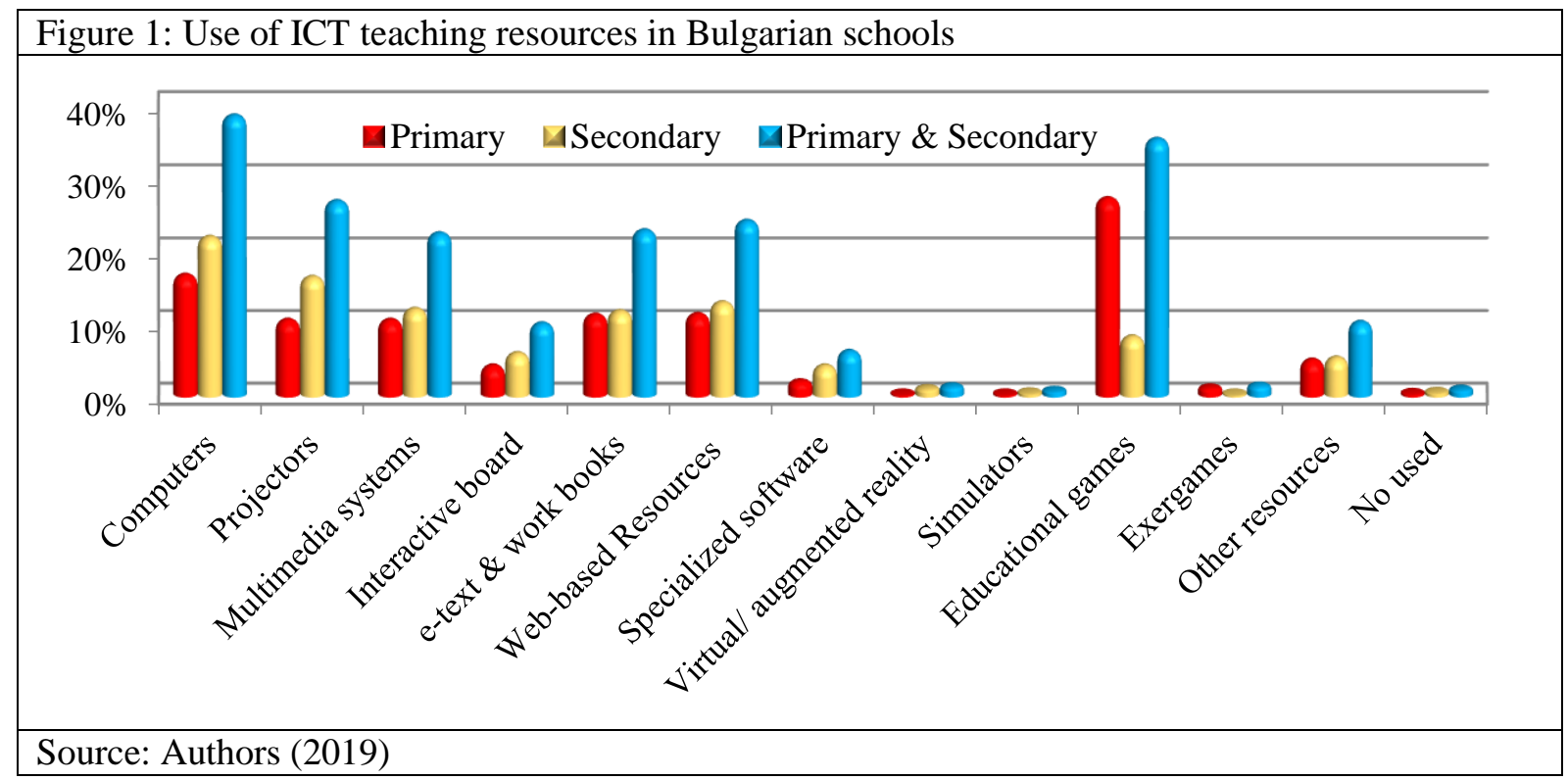

In the survey many teachers comment that e-learning resources for some subject topics are too scarce, scattered across the web, often of low quality, and usually do not meet the government educational standards. One of the possible solutions is to build an especially dedicated site for educational resources, where they are listed by category and to be provided with both descriptions and links. It is a good idea for there to be available many free and open educational resources and software. The survey findings show that in most of the schools, many technology tools are available, but they are usually not connected in an e-learning system. Their integration in a common framework will contribute to their more frequent and efficient use.

\section{Smart Learning Environment and Smart Teaching}

Nowadays traditional schools begin to change their appearance. A wide variety of connected, innovative technology tools transform learning environments completely. Thus, a vast range of smart devices enables smart teaching approaches where students participate in real science experiments and explorations thanks to the IoT and virtual/ augmented reality without even leaving classrooms. The authors conceptualize this process of transformation in the functional scheme of the teaching process in a smart classroom presented in Figure 2.

As presented in detail in Savov et al. (2018), the authors propose a set of smart sensors and actuators together with a module for the control of a classroom environment that performs some actions by itself. The teacher can also handle them depending on the current circumstances. The educational resource module managed by the teacher supplies the necessary learning items. This module communicates with the classroom environment module to arrange the appropriate scene, situation, ambience, and 
background for the ongoing lesson. This may include audio and video effects, air streams etc. to demonstrate various characteristics of the teaching materials presented.

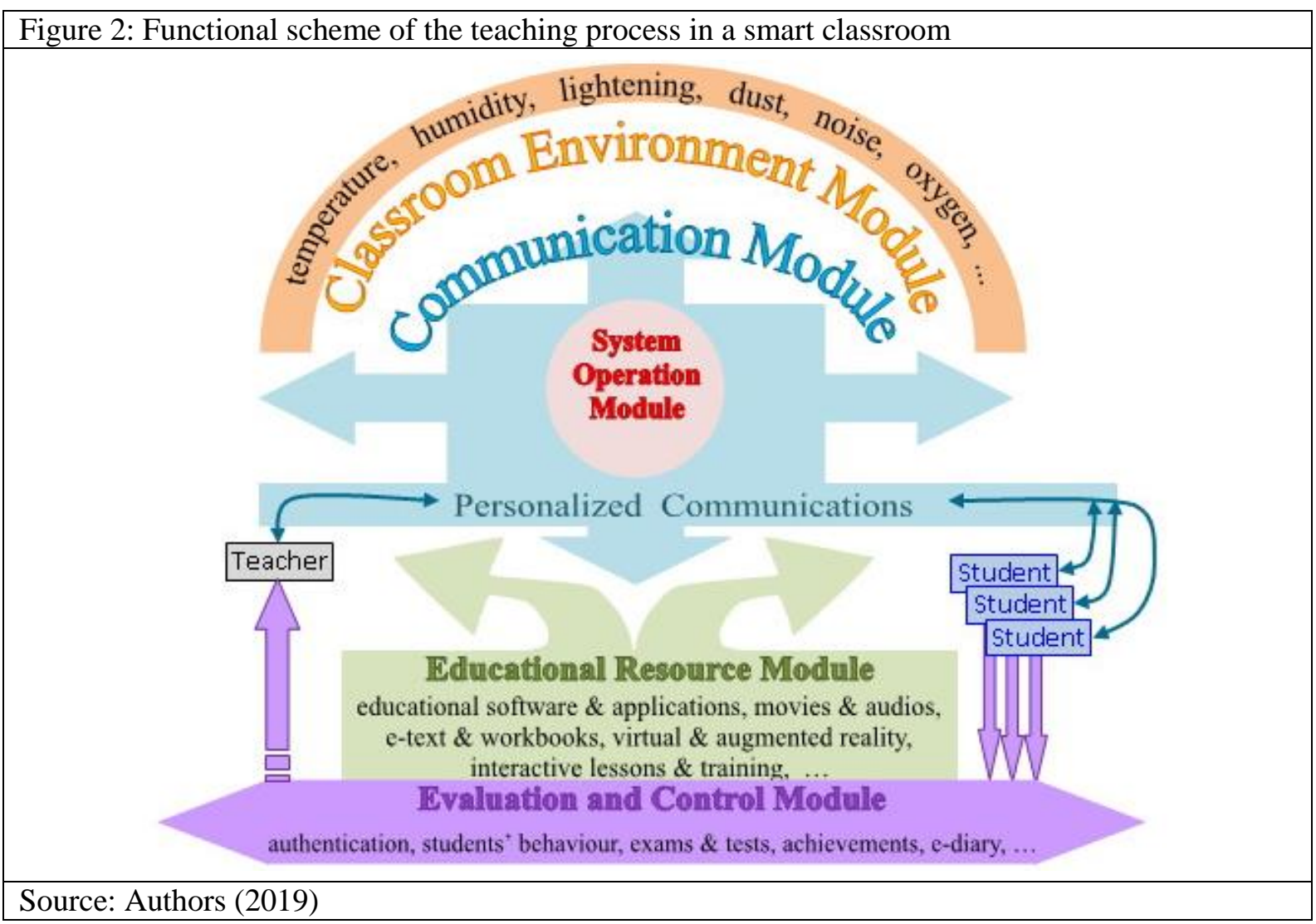

The efficiency of study depends on conditions as well as on appropriate learning materials and the individual learning pace of each student. Modern classrooms have to ensure learning comfort and enable the delivery of "individually tailored" learning materials for each student (content, tasks, and tests). The conditions can be of environmental and personal origins. The first one is physical parameters ergonomics, temperature, direct sunlight, background noise, brightness. The second one is of physiological (hunger, thirst, health status) and psychological character (positive and negative). The learning specificities of each student define the appropriate requirements related to the learning process. Most of the students absorb the material at approximately the same pace. But there are students, who acquire the tasks faster or slower. The build-in IoT (sensors and actuators) can make the traditional education "smart" and enables to spot these cases, to recognize problems, react appropriately and solve them. The timely addressing of the problems by the personal attention of the teacher ensures reliance, calmness and ultimately leads to motivation and better results.

Essential for education is not only the provision of knowledge, skills, and tests but also the offering of alternative ways of teaching or additional learning materials. Teachers need to be aware of the progress of the individual students during the lessons. The design and development of functional "smartness" of education require the participation of professionals (teachers, educators, psychologists, speech therapists, etc.). As already discussed in Terzieva et al. (2016), a personal profile portfolio serves as a base for preparing an individual curriculum where data essential to the student's learning style are available.

ICT and especially IoT can provide multisensory access to real-world phenomena and make education an inspiring and challenging experience. The use of innovative technologies aids individual teaching by meeting specific requirements, adapting and personalizing the learning process, and applying different teaching approaches. A higher degree of integration of students with difficulties can also be achieved.

\section{Need of One Classroom for All}

Modern ICT tools can considerably contribute to improving the quality of education in an integrated environment. Networked smart devices (sensors, actuators, cameras, microphones, tablets, computers, 
and smartphones) can automatically adjust lightings, heating, and air quality. They can register and report any problems and provide management functionalities for specific processes, such as presenting additional information about a particular student; individually determining the level of difficulty or the type of task assigned to each learner. For instance, if a particular student has hearing problems or the level of background noise in the classroom is very high and hampers a clear perception of the teacher's general guidelines, in this case, a personal audio channel will facilitate communication. It is not difficult to achieve such a link with modern technology. On the one hand, it does not interfere with other students, since only the particular student receives instruction from the teacher. On the other hand, the pupil feels more comfortable when having personal contact and attention of the teacher. The physical link also has a positive psychological impact.

A significant aspect of contemporary education policy is to provide teaching to children with different learning difficulties (such as visual, auditory, motor, hyperactivity, and dyslexia) along with other students. The goal is to integrate such children so that they can also take an active part in the learning process and social life in school, be together with their classmates, feel part of the whole and not be isolated. The integration will later help them in life and contribute, to their self-esteem, motivate them to collaborate with other children, both in learning and in games. Further, it will raise tolerance toward others, and at the same time provide knowledge about the existence of students with various problems as well as how to respond and assist in case of an incident.

\section{Communication module}

The practical part of the current research offers a solution for providing communication between diverse subjects and objects of the educational process. The focus is on the communication module (CM) as one of the pivotal parts in the suggested structural model of the smart classroom in Savov et al. (2017). The primary purpose of a $\mathrm{CM}$ is to create a flexible and sustainable communication system in order to perform two essential tasks - ensuring communication between students and teacher as well as the involvement of parents in the educational process. The architecture of the CM mainly consists of two submodules: the Interactive classroom system and the Parental control system.

The Interactive classroom system (ICS) is a complex of network-connected devices that support the learning process by allowing users (subjects of educational process) to execute different educational tasks and exercises in real time simultaneously. The hardware implementation of the system for a single classroom includes finger touched interactive whiteboards, embedded system development boards (ESDB), touch screen displays, input devices as keyboards, mice, headphones and microphones. A significant element of the current experimental examination is the use of ESDB instead of personal computers (PC). The significantly cheaper price, smaller dimensions and sufficient computational power are the primary considerations for the authors to choose ESDB for performing the defined tasks. The use of ESDB can provide an economically efficient way of equipping a classroom with the necessary computers for all students. The market offers an enormous variety of ESDM with a wide range of technical parameters at a reasonable price. Concerning all requirements of ICS and foreseeing some future upgrades of the system, a Raspberry Pi $3 \mathrm{~B}+$ model was chosen as an appropriate board - more details in The Mag Pi. The implementation of this board as a central structural unit of ICS allows to build a stable communication, to attach all the peripherals registering student's interaction during the performance of learning tasks and the use of specific applications. A network between stationary attached devices is set up by Ethernet, while some mobile devices are connected by dual-band $2.4 \mathrm{GHz}$ and $5 \mathrm{GHz}$ wireless LAN. Both types of connections provide reasonable network traffic and fulfil all service requirements concerning the learning process. The used board has functionalities for setting up Bluetooth as an alternative network that involves different devices like smartphones and tablets in classroom activities. The technical architecture of the board has 4 USB 2.0 ports that provide attachment of various Input/ Output devices. A significant constructively feature of the selected board is the absence of a microphone jack, which enforces us to use an additional USB microphone. The headphones could be connected to 4-pole $3.5 \mathrm{~mm}$ audio jack on the board. Another specific characteristic of this board is a High-Definition Multimedia Interface (HDMI) as an output for a video signal that allows using different types of monitors including touch-sensitive screens. The operation system installed on the board is Raspbian, which delivers a broad spectrum of possibilities for developing specific learning applications and different tasks to provide a better understanding of the learning material. The Python programing language could be used for creating diverse educational applications and adapting them to specific 
requirements of the learning subject. Multimedia features of the suggested ICS offer plenty of options which teachers can use when lecturing and exanimating. ICS is applicable in performing different listening tasks as a part of linguistics classes.

A parental control system (PCS) aims to inform parents of all student's grades, presence and coming examination or specific learning activities. The system is a web-based event reminder that has access to school records for students. Technically, PCS is based on a Raspberry Pi 3B+ module and Raspberry Pi 3G-4G/LTE Base Shield. The access to an electronic diary and notification system panel is provided by web and database servers running on the board. An ad-hoc software algorithm is responsible for sending short messages and emails to parents regularly according to their preferences. PCS has a user-friendly interface which allows making different settings concerning the notification service a straight forward process.

\section{Conclusion}

The information environment we live in requires not only a new look at the world, but also a new way of communication and work, a new philosophy, and a new style of teaching. Nowadays schools lose their charm as an attractive place where new things are learned. Educational institutions already have started to actively incorporate technologies into learning, mainly to ensure the connection between teachers and students, linking processes, sharing data and many other applications. The saturation of the classroom with ICT tools can turn over this situation and transform teaching beyond recognition. IoT can impact education further - to help the adoption of new practices and to make teaching more realistically and relevant through engagement beyond the classroom. The developed conception of smart classrooms allows the integration of all available technology tools and resources. Until recently, the multimedia systems were good enough to demonstrate different phenomena and present audio-visual materials. However, through innovative technology tools, immersion in virtual or augmented reality can be achieved. The expected benefits are a dramatic increase in interest in each subject, engagement with the learning material, a better understanding and efficient knowledge perception. In this regard, technologies such as virtual and augmented reality (launched by digital games and simulators) can play a significant role. Hence, schools can become a place where "things happen " and provide interesting experiences: wandering in a desert or jungle, immersing in the ocean, flying in space, close observation of historical battles, hikes or adventures, performing complex experiments, going through exciting novels. Technology equipment can be used in teaching to present, visualize, and exercise the learning material; for learning through games, and testing knowledge acquisition and skills.

\section{Acknowledgements}

This research was supported by the Bulgarian FNI fund through the project "Conceptual Modeling and Simulation of Internet of Things Ecosystems (KoMEIN)

\section{References}

Alghamdi, A., Shetty, S. (2016). Survey: Toward a smart campus using the Internet of Things. IEEE Future Internet of Things and Cloud Proceedings, doi:10.1109/FiCloud.2016.41

Ali, M., Bilala, S. M., Razzaqa, M. A., Khana, J., Leea, S., Idrisb, M., Aazamc, M., Choid, T., Hane, S. C., \& Kange, B. H. (2017). IoTFLiP: IoT-based flipped learning platform for medical education. Digital communications and networks, 3(3), 188-194. doi:10.1016/j.dcan.2017.03.002

Banica, L., Burtescu, E. \& Enescu, F. (2017). The impact of Internet of Things in higher education. Scientific Bulletin Economic Sciences, University of Pitesti, 16(1), 53-59. Retrieved from: http://economic.upit.ro/RePEc/pdf/2017_1_6.pdf

Banks, L. (2015). Overview of IBM Cloud Services and Academic Initiatives. Retrieved from https://www.ibm.com/ibm/files/Q411327R22959D03/1_Lysa_Banks.pdf

Cata, M. (2015). Smart university a new concept in the Internet of Things. Networking in Education and Research (RoEduNet NER 2015) Proceedings, 195-197.

Digital Bulgaria 2025. (2018) Retrieved from http://www.strategy.bg/PublicConsultations/View.aspx?lang=bg-BG\&Id=3399

Heinemann, C. \& Uskov, V. L. (2018). Smart University: Literature review and creative analysis In V. L. Uskov, J. P. Bakken, R. J. Howlett, \& L. C. Jain (Eds.) Smart Universities: Concepts, Systems and Technologies, (11-46), Springer International Publishing AG. doi:10.1007/978-3-319-59454-5_2

Nati, M., Gluhak, A., Abangar, H. \& Headley, W. (2013). SmartCampus: A user-centric testbed for Internet of Things experimentation. IEEE Wireless Personal Multimedia Communication WPMC2013 Proceedings, 1-6. Retrieved from: http://www.smartsantander.eu/downloads/Presentations/gws13.pdf 
Savov, T., Terzieva, V., Todorova, K. (2018). Computer Vision and Internet of Things: Attention System in Educational Context. In Rachev \& Smrikarov (Eds.) CompSysTech'18 Proceedings, ACM, New York, NY, USA, 171-177. doi: $10.1145 / 3274005.3274014$

Savov, T., Terzieva, V., Todorova, K., Kademova-Katzarova, P. (2017). Contemporary technology support for education, CBU2017 Innovations in Science and Education Proceedings (Vol. 5), 802-806.

Selinger, M., Sepulveda, A. \& Buchan, J. (2013) Education and the Internet of Everything: How ubiquitous connectedness can help transform pedagogy. Retrieved from https://www.cisco.com/c/dam/en_us/solutions/industries/docs/education/education_internet.pdf Smart Classroom platform. Retrieved from http://www.smartclassroom.bg/

Strategy for effective implementation of information and communication technologies in education and science in the republic of Bulgaria (2014-2020). (2014). Retrieved from http://www.strategy.bg/StrategicDocuments/View.aspx?Id=904

Terzieva, V., Paunova-Hubenova, E., Dimitrov, S., Dobrinkova N. (2018). ICT in Bulgarian schools - Changes in the last decade. EDULEARN18 Proceedings, 6801-6810. doi:10.21125/edulearn.2018.1612

Terzieva, V., Savov, T., Todorova, K., Andreev, R. \& Kademova-Katzarova, P. (2017). Internet of Things in education: Smart environment. ICERI2017 Proceedings, 4679-4685. doi:10.21125/iceri.2017.1256

Terzieva, V., Todorova, K., Kademova-Katzarova, P. (2016). IoT in schools: Smart classroom, personalized environment. BdKCSE'2016 Proceedings, 87-96. Retrieved from http://conference.ott-iict.bas.bg/wpcontent/uploads/2017/01/BdKCSE_2016_Preprint-Version.pdf

The Mag Pi - the official Raspberry Pi magazine (2018). Retrieved from: https://www.raspberrypi.org/magpiissues/MagPi68.pdf

Zhu, Zh-T., Yu, M-H. \& Riezebos, P. (2016). Smart learning environments 3(4), doi:10.1186/s40561-016-0026-2

Rudd, J., Davia, Ch. \& Sullivan P. (2009). Education for a Smarter Planet: The Future of Learning. Retrieved from http://www.redbooks.ibm.com/redpapers/pdfs/redp4564.pdf 